\title{
Predictors of Short Term Outcomes of Primary Percutaneous Coronary Intervention
}

\author{
Farhana Ahmed ${ }^{1}$, Afzalur Rahman ${ }^{1}$,Mohammad Arifur Rahman ${ }^{1}$, Tariq Ahmed Chowdhury ${ }^{1}$, Md. Shahabul Huda \\ Chowdhury², Syed Nasir Uddin ${ }^{1}$, AKM Monwarul Islam¹, Mohsin Ahmed ${ }^{1}$
}

\begin{abstract}
:
Background: Acute myocardial infarction (AMI) is one of the leading causes of death and disability all over the world. Primary percutaneous coronary intervention $(\mathrm{PCl})$ is the treatment of choice for patients with acute ST segment elevation myocardial infarction (STEMI). Primary $\mathrm{PCl}$ is being increasingly done in our country also. But the factor influencing the outcome of primary $\mathrm{PCl}$ in our setting are mostly unknown. The present study was conducted to investigate factors that influencing the short term outcomes of primary PCI.

Materials and methods: This prospective observational study was conducted from September 2014 to January 2016in the Department of Cardiology, National Institute of Cardiovascular Diseases (NICVD), Dhaka. 48 patients were selected by purposive sampling. Patients with acute STEMI treated with primary $\mathrm{PCl}$ were included in the study based on inclusion and exclusion criteria. Effect of factors including advanced age, male sex, diabetes mellitus, hypertension, dyslipidemia, serum creatinine, left ventricular ejection fraction, anterior myocardial infarction (MI), thrombolysis in myocardial infarction (TIMI) flow, multi vessel disease, angiographic severity score (Leaman score), thrombus aspiration, door to balloon time and total ischemic time
\end{abstract}

on major adverse cardiac events (MACE) i.e. death, post procedural MI, target vessel revascularization (TVR), stroke as well as, on other adverse events like heart failure, cardiogenic shock, major bleeding, significant arrhythmia and stent thrombosis were studied.

Results: The overall incidence of MACE was $2.1 \%$, major bleeding $2.1 \%$, heart failure $4.2 \%$ and cardiogenic shock $\mathbf{2 . 1 \%}$. In multivariate analysis, the factors independently influencing the adverse short term outcomes (MACE and other adverse events) were diabetes mellitus (odds ratio (OR) 2.55, 95\% confidence interval (CI) 1.180 to $4.124, \mathrm{p}=0.02$ ), anterior MI (OR $1.48,95 \% \mathrm{Cl} 1.020$ to $1.926, p=0.04)$, total ischaemic time (OR $1.49,95 \% \mathrm{Cl} 1.044$ to 2.444, $\mathrm{p}=\mathbf{0 . 0 4}$ ), multivessel coronary artery disease (OR 1.77, 95\% Cl 1.26 to $3.261, p=0.03$ ) and Leaman score (OR 2.5, 95\% Cl 1.100-4.504, $\mathrm{p}=.03$ ).

Conclusion: According to our finding, diabetes mellitus, anterior myocardial infarction, total ischemic time, multivessel coronary artery disease and high Leaman score are predictors of adverse short term outcomes of primary $\mathrm{PCI}$.

Key word: Percutaneous Coronary Intervention, Primary, STEMI, Short Term Outcomes.

(Bangladesh Heart Journal 2018; 33(2): 112-120)

Introduction:

Coronary artery disease (CAD) is the most common form of heart disease and single most important cause of

1. National Institute of Cardiovascular Diseases, Dhaka, Bangladesh

2. Government Employee Hospital, Dhaka, Bangladesh.

Address of Correspondence:Farhana Ahmed, Registrar, Dept. of Cardiology ,National Institute of Cardiovascular Diseases, Dhaka, Bangladesh, Mobile-+8801712282059, Email-nipaariha79@gmail.com premature death in most part of the world. Acute myocardial infarction (AMI) is one of the leading causes of death and disability. It generally occurs due to sudden occlusion of a coronary artery by formation of thrombus at the site of fissured or ruptured atherosclerotic plaque. ${ }^{1}$ The major aspect of treatment of ST elevated Myocardial Infarction (STEMI) is reperfusion of the infarct related artery.

DOI: http://dx.doi.org/10.3329/bhj.v33i2.39307

Copyright (C) 2017 Bangladesh Cardiac Society. Published by Bangladesh Cardiac Society. This is an Open Access articles published under the Creative Commons Attribution-NonCommercial 4.0 International License (CC BY-NC). This license permits use, distribution and reproduction in any medium, provided the original work is properly cited and is not used for commercial purposes. 
Reperfusion therapy aims at restoration of antegrade flow in the occluded infarct related artery, which reduce infarct size and improves clinical outcome. ${ }^{2}$ Early, effective and sustained reperfusion of the culprit artery is needed to salvage myocardium, maintain left ventricular function, and reduce mortality.

Fibrinolysis and primary $\mathrm{PCl}$ are the two options for the patient presenting with STEMI. If high-quality $\mathrm{PCl}$ is available, multiple randomized trials have shown enhanced survival compared to fibrinolysis with a lower rate of intracranial hemorrhage and recurrent myocardial infarction (MI). ${ }^{3}$

Outcomes after primary $\mathrm{PCl}$ are variable and accurate risk stratification is the clinical importance in guiding the management of relatively high risk patient. Some studies have shown that mortality rates are higher among women than in men. ${ }^{4}$ Moreover, some studies have identified high age as a predictor of major adverse cardiac events (MACE) after primary $\mathrm{PCI}$ for myocardial infarction. ${ }^{5}$ Patients with diabetes who receive primary $\mathrm{PCl}$ for STEMI are also at higher risk of mortality especially during hospitalization and the first year following the procedure. ${ }^{6}$ In patients with myocardial infarction, high lipoprotein (a) levels have been found to be associated with adverse long-term result. ${ }^{7}$

Finally, shorter interval between the onset of myocardial infarction symptoms and primary $\mathrm{PCI}$ will lead to better result. The most favorable interval has been determined as 90 minutes. ${ }^{8}$ Diabetes mellitus, poor post-interventional flow in the coronary arteries, three vessels disease, cardiogenic shock, and infarct localization appear to be important factors impacting the outcome in patients with STEMI undergoing primary $\mathrm{PCl}$. Primary $\mathrm{PCl}$ is being increasingly done successfully in our country also. No such study done so far in our population to determine factors influence the outcomes of primary $\mathrm{PCl}$. The present study was conducted to determine factors that influence the outcomes of patients who underwent primary $\mathrm{PCl}$ due to acute myocardial infarction.

\section{Study Methods:}

This prospective observational study conducted in the department of Cardiology, National Institute of Cardiovascular Diseases (NICVD), from September 2014 to January 2016. Objective of the study was to find out the predictors of short term outcomes of primary $\mathrm{PCl}$ among Bangladeshi population presented with acute ST segment elevation myocardial infarction (STEMI). Total 48 patients with acute STEMI presented within 12 hours of onset of typical chest pain were included in the study purposively. Patients who received fibrinolytic therapy, having old $\mathrm{MI}$, LBBB, valvular heart disease, cardiomyopathies, renal failure, high bleeding risk, stroke, malignancy were excluded from the study.

All patients were subjected to a thorough assessment of history with a focus on demographic data, analysis of chest pain, including timing variable, risk factors of coronary artery disease, drug history. Physical examination was performed including vital signs and evidence of heart failure $\left(\mathrm{S}_{3}\right.$ gallop, pulmonary rales, elevated JVP). ECG was done immediately. STEMI was diagnosed by new ST elevation at the $\mathrm{J}$ point in at least 2 contiguous leads of $\geq 2 \mathrm{~mm}(0.2 \mathrm{mV})$ in men or $\geq 1.5 \mathrm{~mm}(0.15 \mathrm{mV})$ in women in leads $\mathrm{V} 2-\mathrm{V} 3$ and/or of $\geq 1 \mathrm{~mm}(0.1 \mathrm{mV})$ in other contiguous chest leads or the limb leads. Loading dose of aspirin and clopidogrel was given immediately after diagnosis of acute STEMI. Blood sugar was checked immediately by glucometre and managed accordingly. Blood sample send for lipid profile, troponin-I, serum creatinine before coronary angiogram; left ventricular function was assessed by echocardiography by Teichholz method before coronary angiogram.

Immediately coronary angiography was done by femoral route to identify the culprit lesion, thrombus burden, other vessels involvement; severity of coronary artery disease were also assessed by vessel score and Leaman score. Coronary flow in the infarct related artery was assessed visually by the operator and classified according to the TIMI grading system on a scale of 0 to III. During primary $\mathrm{PCI}$, pre-dilatation of lesion and thrombus aspiration was performed by aspiration catheter in selected cases, then PTCA (percutaneous transluminal coronary angioplasty) with stenting was done and post procedural TIMI flow was assessed and post-dilatation was done if necessary. Successful PCl was defined as visually assessed $<20 \%$ residual stenosis with TIMI III distal flow and absence of major clinical complications (death, AMI and emergency myocardial revascularization). During hospital stay, patients were examined daily to find out any major complications following $\mathrm{PCl}$; troponin-I and serum creatinine were repeated 6 hours after $\mathrm{PCl}$; left ventricular function following $\mathrm{PCl}$ was assessed by echocardiography before discharge. All patients were asked for follow up within one month after primary $\mathrm{PCl}$. In each follow up following parameter were seen: haemodynamic (pulse, blood pressure), ECG (ST change) and complications including MACE (death, Post procedural Myocardial Infarction and the need for repeat revascularization, Stroke) and other adverse events including major bleeding (Major bleeding defined as either intracranial bleeding or overt bleeding with a decrease in hemoglobin $\geq 5 \mathrm{~g} / \mathrm{dl}$ ), heart failure, cardiogenic shock, significant arrhythmia. Follow up evaluation was done by telephone interview for those who could not attend directly and all 
parameters were recorded. The primary end point was inhospital MACE andother adverse events and secondary end point included 30 days outcome from discharge including MACE and other adverse events.

\section{Statistical Methods}

All variables were entered into the Statistical Package for Social Sciences, version 16 (SPSS Inc., Chicago, Illinois).Data was presented as frequency and percents for categorical variables and as mean with standard deviation for quantitative variables. Univariate and multivariate regression analysis were done with variables may be related to adverse outcome with calculated risk ratios odds ratios [OR] for independent variables with $95 \%$ confidence intervals $[\mathrm{Cl}]$. $P$ value $<0.05$ were considered as significant.

\section{Results:}

This prospective observational study was conducted in NICVD, Dhaka starting from September 2014 to January 2016. A total of 48 patients with acute STEMI who had fulfilled the inclusion and exclusion criteria were included in the study.

The mean age of this study group was found $47.9 \pm 6.5$ years and the age limit was 37 to 65 years (Fig-1); $85 \%$ study population were male and remaining $15 \%$ were female

(Fig-2). Smoking was the most prevalent risk factor affecting $75.0 \%$. Table-1 shows that hypertension, diabetes mellitus,dyslipidemia was found in $41.7 \%, 45.8 \%, 54.2 \%$ study population respectively; along with chest pain $16.8 \%$ and $22.9 \%$ patients were presented with shortness of breath and palpitation; the mean systolic blood pressure of study population was $112.5 \pm 23.6 \mathrm{mmHg}$ and mean diastolic blood pressure was $69.6 \pm 14.3 \mathrm{mmHg}$; JVP was raised in $4.2 \%$ patients on admission; heart failure and arrhythmia were present in $4.2 \%$ patients each, mean pain to door time was $4.6 \pm 1.8 \mathrm{hrs}$, door to balloon time was $1.9 \pm .9 \mathrm{hrs}$, total ischemic time was $6.8 \pm 2.1 \mathrm{hrs}$.

Anterior infarction was found in $47.9 \%$ patient and rest were presented with inferior MI. Coronary angiogram revealed 2.1\% patients had LM disease; LAD and RCA were involved in $33.3 \%$ patients each. LCX involved in $4.2 \%$ cases, both LAD and LCX were involved in $10.4 \%$ patients. LAD and RCA, LCX and RCA were involved in $4.2 \%$ patients each. Triple vessel (LAD, LCX and RCA)were involved in $8.3 \%$ patients. Fig-3 shows that single vessel involvement was found in $72.9 \%$ followed by double vessel $18.8 \%$ and triple vessel $8.3 \%$ among the study population $(n=48)$.Mean lesion length was found $23.1 \pm 9.1 \mathrm{~mm} . \mathrm{PCl}$ to non culprit lesion was done in $4.2 \%$ cases, thrombus aspiration and predilatation were done in $33.3 \%$ and $12.5 \%$ cases respectively.
Mean Leaman score of study population was $11.4 \pm 5$.9.Fig4 shows that drug eluting stent were used in $72.9 \%$ of cases and bare metal stent were used in $27.1 \%$ of cases.Before $\mathrm{PCI}$ 95.8\% patients had TIMI 0 and $4.2 \%$ patients had TIMI I flow. On the contrary, in post-PCI TIMI III flow resumed in 93.8\% cases and $6.2 \%$ patients had TIMI II flow

(Fig-5). Table-2 shows adverse in-hospital and 1 month outcomes of the study population $(n=48)$ where it was found that death, heart failure, major bleeding and cardiogenic shock developed in $2.1 \%, 4.2 \%, 2.1 \%$ and $2.1 \%$ cases respectively. Binary logistic regression analysis of odds ratio for characteristics of the population likely to develop adverse outcomes of primary $\mathrm{PCI}$. In regression analysis (Table-3) diabetes mellitus, anterior $\mathrm{MI}$, total ischemic time, multivessel disease and Leaman score were found to be the independent predictors for developing adverse short term outcomes of primary $\mathrm{PCl}$.

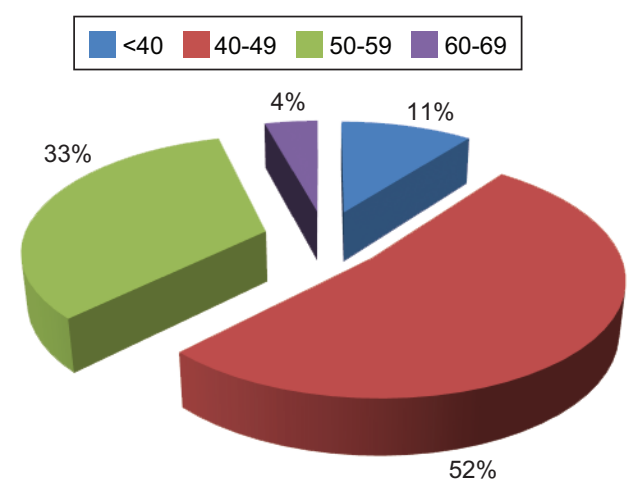

Fig.-1: Age distribution of study population $(n=48)$

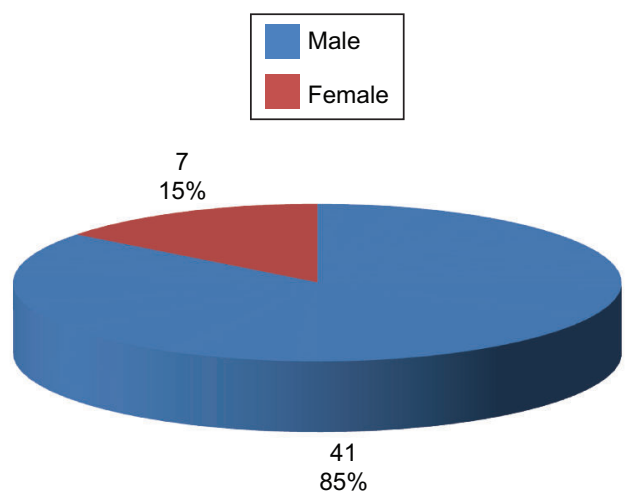

Fig.-2: Sex distribution of study population ( $n=48)$ 


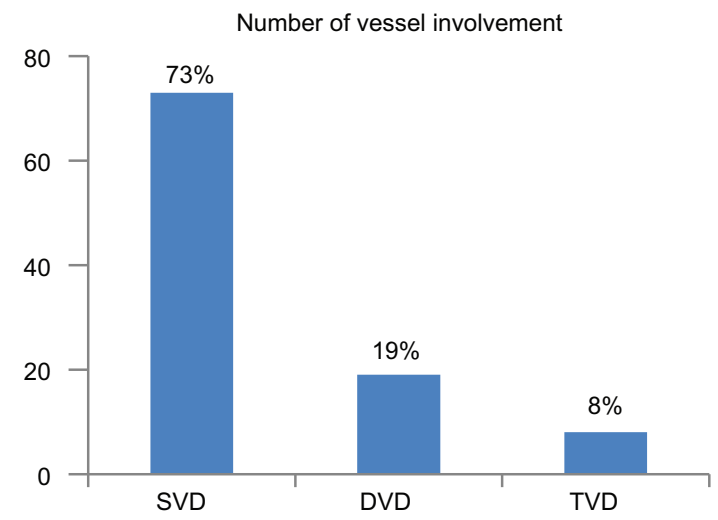

Fig.-3: Distribution of study population according to number of vessel involvement

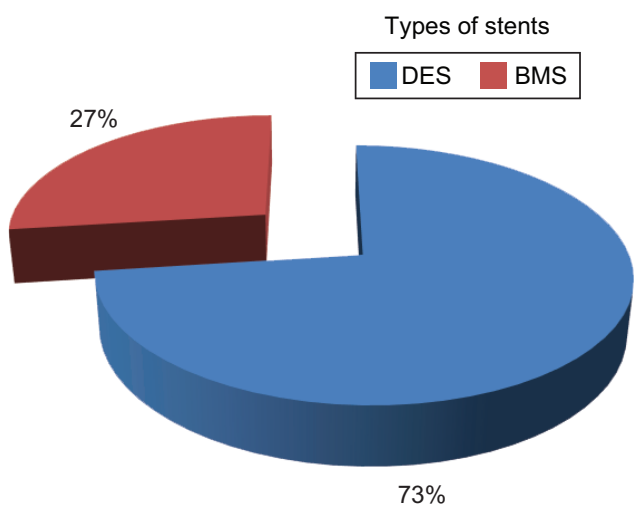

Fig.-4: Distribution according to type of stent used in study population $(n=48)$

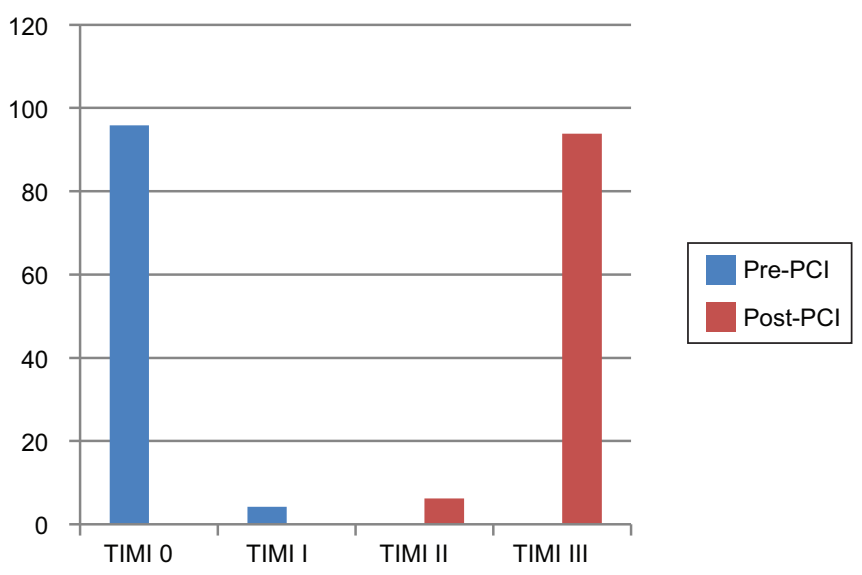

Fig.-5: Procedural outcomes of the study population according to TIMI flow ( $n=48)$

Table-I

Baseline characteristics of study population

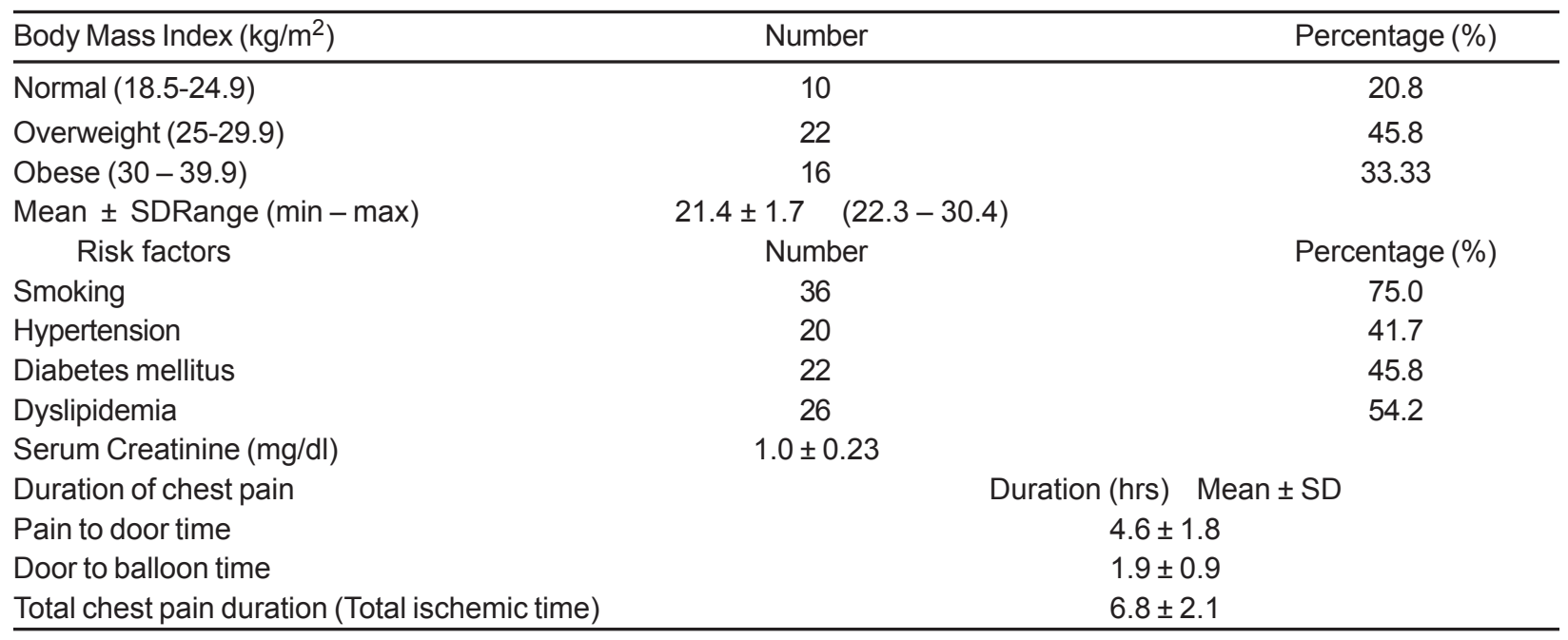


Table-II

Adverse in-hospital and 1 month outcomes of the study population $(n=48)$

\begin{tabular}{lccc}
\hline Outcomes & $\begin{array}{c}\text { In hospital } \\
\text { Number (\%) }\end{array}$ & $\begin{array}{c}1 \text { month } \\
\text { Number (\%) }\end{array}$ & $\begin{array}{c}\text { Total } \\
\text { Number (\%) }\end{array}$ \\
\hline MACE & $1(2.1)$ & & $1(2.1)$ \\
Death & $1(2.1)$ & 0 & 0 \\
M & 0 & 0 & 0 \\
TVR & 0 & 0 & 0 \\
Stroke & 0 & 0 & $1(2.1)$ \\
Other adverse events & $1(2.1)$ & 0 & $2(4.2)$ \\
Major bleeding & $1(2.1)$ & $1(2.1)$ & $1(2.1)$ \\
Heart failure & $1(2.1)$ & 0 & 0 \\
Cardiogenic shock & 0 & 0 & 0 \\
Significant Arrhythmia & 0 & 0 & \\
Stent thrombosis & & &
\end{tabular}

Table-III

Factors related to adverse short term outcomes of primary $\mathrm{PCl}$

\begin{tabular}{|c|c|c|c|c|c|c|}
\hline \multirow[t]{2}{*}{ Variables of interest } & \multicolumn{3}{|c|}{ Univariate analysis } & \multicolumn{3}{|c|}{ Multivariate analysis } \\
\hline & OR & $95 \% \mathrm{Cl}$ of $\mathrm{OR}$ & $p$ value & OR & $95 \% \mathrm{Cl}$ of OR & $p$ value \\
\hline Age (>50 years) & 1.89 & $0.797-3.538$ & $0.17^{\mathrm{ns}}$ & 1.59 & $0.699-3.443$ & $0.16^{\text {ns }}$ \\
\hline Male gender & 1.02 & $0.989-1.431$ & $0.36^{\mathrm{ns}}$ & 1.00 & $0.987-1.132$ & $0.42^{\text {ns }}$ \\
\hline Current smoking & 1.58 & $0.797-3.538$ & $0.16^{\text {ns }}$ & 1.55 & $0.699-3.443$ & $0.26^{\text {ns }}$ \\
\hline Diabetes mellitus & 3.04 & $1.190-4.931$ & $0.01^{\mathrm{s}}$ & 2.55 & $1.180-4.124$ & $0.02^{\mathrm{s}}$ \\
\hline Hypertension & 1.11 & $0.202-2.401$ & $0.21^{\mathrm{ns}}$ & 0.91 & $0.107-2.349$ & $0.17^{\text {ns }}$ \\
\hline Dyslipidaemia & 1.24 & $0.404-2.530$ & $0.14^{\mathrm{ns}}$ & 1.19 & $0.301-2.429$ & $0.11^{\text {ns }}$ \\
\hline Serum creatinine & 0.86 & $0.120-2.549$ & $0.30^{\mathrm{ns}}$ & 0.77 & $0.109-2.409$ & $0.39^{n s}$ \\
\hline Anterior Ml & 1.96 & $1.050-2.599$ & $0.03^{s}$ & 1.48 & $1.020-1.926$ & $0.04^{\mathrm{s}}$ \\
\hline LVEF & 1.97 & $0.594-1.789$ & $0.14^{\mathrm{ns}}$ & 1.11 & $0.449-1.680$ & $0.20^{\mathrm{ns}}$ \\
\hline Total ischemic time & 1.92 & $1.089-2.779$ & $0.03^{s}$ & 1.49 & $1.044-2.444$ & $0.04^{\mathrm{s}}$ \\
\hline Door to balloon time & 0.97 & $0.080-1.608$ & $0.40^{\mathrm{ns}}$ & 0.86 & $0.050-1.480$ & $0.46^{\mathrm{ns}}$ \\
\hline Multivessel disease & 2.01 & $1.142-3.144$ & $0.02^{s}$ & 1.77 & $1.26-3.261$ & $0.03^{s}$ \\
\hline Pre-TIMI (0) & 1.24 & $0.624-3.540$ & $0.11^{\mathrm{ns}}$ & 1.00 & $0.509-2.780$ & $0.15^{\text {ns }}$ \\
\hline Leaman score & 2.78 & $1.201-5.404$ & $0.01^{\mathrm{s}}$ & 2.50 & $1.100-4.504$ & $0.03^{s}$ \\
\hline Thrombus aspiration & 0.97 & $0.090-1.799$ & $0.25^{\text {ns }}$ & 0.86 & $0.040-1.690$ & $0.22^{\text {ns }}$ \\
\hline
\end{tabular}

\section{Discussion:}

Coronary artery disease is one of the most important causes of death worldwide. However, $\mathrm{PCl}$ represents one of the cornerstone management modalities for patients with coronary artery disease. To date, data are lacking on the factors that modify the outcomes of primary $\mathrm{PCl}$ in Bangladesh. This study sought to identify factors affecting major adverse cardiac outcomes in patients who underwent primary PCI for STEMI.

In our study, mean age of patient with acute STEMI was $47.9 \pm 6.5$ years and most of the patients were between 40 to 49 years instead of old age group as seen in Western communities. ${ }^{9}$ In our observation, the incidence of MACE were not related with age, increased age generally increase the mortality in patient with myocardial Infarction ${ }^{10}$, Since we have lacking patient of very old age group, so this result is justifiable.

Most of our patients were male (85\%) which reflect the current scenario that coronary artery disease is more common in man. ${ }^{9}$ Though most of our patients were men, we found no significant effect of sex on major adverse cardiac outcomes which is similar to a study done 
previously. ${ }^{11}$ However, some studies have found higher mortality rates in women than in men. ${ }^{4}$ The absence of such a higher risk among our female participants emphasizes the benefits of primary $\mathrm{PCl}$ in women.

Smoking is a well known risk factor for coronary artery disease. Most of our study population $(75 \%)$ were smoker. The importance of smoking in the incidence of major adverse cardiac outcomes after primary $\mathrm{PCl}$ is a matter of concern. In this study, smoking did not have any effect on MACE. However Both American College of Cardiology and European Society of Cardiology STEMI guidelines strongly encourage the patient and their family to stop smoking and to avoid second hand smoke. ${ }^{12}$

According to global registry for acute coronary events, approximately one in four patients presented with acute coronary syndrome has history of diabetes mellitus ${ }^{13}$. We found a significant number of our study population (45\%) were diabetic and diabetes mellitus was found to be a factor that is responsible for adverse short term outcome after primary $\mathrm{PCl}$.

A very recent study report ${ }^{14}$ also described that patients with diabetes mellitus had a worse outcome after primary $\mathrm{PCl}$ than non diabetic patients. Various studies have also highlighted the short-term and long-term effects of diabetes on the MACE. ${ }^{6}$ Thus diabetes mellitus can be considered as a risk factor for major adverse cardiac outcomes after primary $\mathrm{PCl}$ and should give emphasize on good diabetic control for prevention of macro and micro vascular complication and post $\mathrm{PCl}$ adverse outcome.

High arterial blood pressure is a risk factor for coronary artery disease and increases the risk of complications after acute coronary syndrome. ${ }^{15}$ DESERT database ${ }^{16}$ showed that among STEMI patients undergoing primary angioplasty HTN is independently associated with impaired epicardial reperfusion, mortality, re-infarction, TVR and stent thrombosis. In our observation we did not find any significance of hypertension on MACE in patient with primary $\mathrm{PCl}$.

Inter-heart study ${ }^{17}$ suggest that $45 \%$ heart attacks in Western Europe are due to abnormal blood lipid. We found $45.8 \%$ patient with myocardial infarction have dyslipidemia in our study population; a similar study ${ }^{18}$ done in India also found similar incidence $43.6 \%$. Despite the fact that hyperlipidemia is a risk factor for coronary artery disease, we did not find any significant effect on the incidence of major adverse cardiac outcomes in this study.

Better left ventricular function is associated with improved survival. On the other hand, low LVEF leads to higher incidence of MACE. ${ }^{19}$ Although the incidence of heart failure after myocardial infarction has fallen over the last few decades, still it complicating up to $45 \%$ of infarcts. Though in a current study, low LVEF had statistically significant effect on MACE in patients undergoing primary $\mathrm{PCl} ;{ }^{19}$ we did not find any statistically significant correlation of LVEF on MACE after primary $\mathrm{PCl}$ as because of our small number of study population.

Total ischemic time is an important determinant of quality of care. Recommended time as per American College of Cardiology (ACC)/ American Heart Association (AHA) guidelines ${ }^{20}$ is 90 minutes door to balloon time. However achieving this time is possible only in ideal world scenario. In our study, the median door to balloon time was $1.9 \pm .9$ hours. However if we look at recent study conducted in China, the median door to balloon time reported for primary $\mathrm{PCl}$ was $132 \mathrm{~min} .{ }^{21}$ In our study mean of total ischemic time is $6.8 \pm 2.1$ hours. A similar study ${ }^{22}$ describes better outcome of primary $\mathrm{PCl}$ in patients with total ischemic time d"5 hours than in those with longer ischemic time. Treatment within these golden hours of primary PCI results in better myocardial reperfusion and clinical outcomes. Our findings also confirm that prolonged total ischemic time is associated with adverse outcome after $\mathrm{PCl}$.

Anterior myocardial infarction carries the worst prognosis of all infarct locations, mostly due to larger infarct size. In our study, $47.9 \%$ patient were presented with anterior myocardial infarction and rest of the patient with inferior myocardial infarction. A study comparing outcomes from anterior and inferior infarctions found that on an average, patients with anterior $\mathrm{MI}$ had higher incidences of in-hospital mortality (11.9\% vs. $2.8 \%)$, total mortality ( $27 \%$ vs. $11 \%)$, heart failure ( $41 \%$ vs. $15 \%)$ and significant ventricular ectopic activity (70\% vs. $59 \%)$ and a lower ejection fraction on admission ( $38 \%$ vs. $55 \%$ ) compared to patients with inferior MI. ${ }^{23}$ In our study, we also observed that anterior MI had significant (OR 1.48, $p$ value 0.04 ) influence on major adverse cardiac outcomes after primary $\mathrm{PCl}$.

In our observation we found $8.3 \%$ patient with TVD and $18.8 \%$ patient with DVD. Multi vessel involvement has significant (OR 1.77, $p=.03$ ) impact on MACE after primary $\mathrm{PCl}$ which is consistent with a study finding where they also found an increased risk of MACE in presence of multi vessel coronary artery disease. ${ }^{9}$ In the CADILLAC trialcumulative incidence of death of patients with single, double and triplevessel disease was $3.2 \%, 4.4 \%$ and $7.8 \%$, respectively $(p=0.003)$, and the composite rate of major adverse cardiac events (MACE) was $14.8 \%, 19.5 \%$ and $23.6 \%$ respectively $(p=0.0006) .{ }^{24}$ In our study, angiographic severity was assessed by Leaman score and higher score was found to have bad prognostic effect on MACE. 
The use of thrombus aspiration during primary $\mathrm{PCl}$ has remained controversial. During our procedure we did manual thrombus aspiration in $33.3 \%$ cases where there were high thrombus burden and we found no significance impact of thrombus aspiration on outcome of procedure which also support the recent recommendation ${ }^{20}$ regarding thrombus aspiration.

Among 48 primary $\mathrm{PCl}$ procedure most of the cases (95.8\%) we did only culprit lesion $\mathrm{PCl}$, only in few cases $(4.2 \%)$ we performed non culprit lesion $\mathrm{PCl}$ also. Multivessel $\mathrm{PCl}$ done in a case where patient presented with $\mathrm{AMI}$ anterior with heart failure and in another cases of acute inferior MI where there were difficulties of identification of culprit lesion, both LCX and RCA revascularization done simultaneously. There were no statistically significant relation observed on short term outcomes in our study, though PRAMI 25 trial showed favorable result of non culprit lesion $\mathrm{PCl}$ beside culprit lesion $\mathrm{PCl}$ in multivessel disease.

Good TIMI flow at the time of angiography and $\mathrm{PCl}$ is a determinant of MACE in patients undergoing primary $\mathrm{PCl}$. In our study, most of the patient (93.8\%) achieved TIMI III flow with excellent procedural success rate after percutaneous coronary intervention. During the time of procedure eight patients developed no-flow phenomenon, after taking appropriate measures TIMI III flow established in five patients and three patients (6.2\%) developed TIMI II flow. Patients with TIMI III flow are expected to have higher survival rates and fewer complications following primary PCl. $^{26}$

Our study showed death rate was only $2.1 \%$; result is consistent with study done in India ${ }^{27}$ and from Pakistan ${ }^{28}$ where in hospital mortality was $2.2 \%$ and $1 \%$ respectively. In our country previous single study conductedhad shown in hospital survival rate only $93.8 \% .{ }^{29}$ In our study population one patient died 3 days after procedure had multiple risk factor including uncontrolled diabetes, hypertension and dyslipidemia,multivessel disease, immediate post procedural period was uneventful, sudden death occur on third day due to ventricular fibrillation.

In our study, among 48 cases in-hospital period death occurred in $2.1 \%$ cases, $2.1 \%$ patient developed heart failure, $2.1 \%$ patient develop cardiogenic shock. Incidence of major bleeding in our study was $2.1 \%$ whereas another study 30 found the incidence of major bleeding is less than $2 \%$. In our study population nobody developed significant arrhythmia though $4.2 \%$ patient developed arrhythmia in the form of ventricular tachycardia, atrial fibrillation immediately after procedure which terminate spontaneously. The frequency of these arrhythmias after primary $\mathrm{PCl}$ was analyzed in Primary Angioplasty in Myocardial Infarction (PAMI) trials. ${ }^{31}$ Within one month period among 48 patient 1 patient took readmission with heart failure all other patients were symptoms free.

\section{Conclusion:}

The study revealed that diabetes mellitus, anterior myocardial infarction, prolonged total ischemic time, multivessel coronary artery disease and high Leaman score of coronary artery disease were predictors of adverse short term outcomes after primary $\mathrm{PCl}$ in Bangladeshi population.

\section{Recommendation:}

Primary $\mathrm{PCl}$ should be encouraged as a management of acute STEMI. Large scale, multicentre study should be done to evaluate the factors which influence the short term outcomes of primary $\mathrm{PCl}$. Diabetic patient should need special attention during primary $\mathrm{PCl}$ and post $\mathrm{PCl}$ period. Multivessel coronary artery disease patient need individualized management strategy.

\section{Conflict of interest - none.}

\section{References}

1. Granger CB, Kenneth WM, Douglas WW, et al. Pexelizumab, an anti C5 complement antibody, as adjunctive therapy to primary percutaneous coronary intervention in acute myocardial infarction: the complement inhibition in myocardial infarction treated with angioplasty (COMMA) trail. Circulation 2006; 108 : 1184-1190.

2. White HD, Norris RM, Brown MA, et al. Effect of intravenous streptokinase on left ventricular function and early survival after acute myocardial infarction. NEJM 1987; 317:850-855.

3. Keeley EC, Boura JA, Grines CL. Primary angioplasty versus intravenous thrombolytic therapy for acute myocardial infarction: a quantitative review of 23 randomized trials. Lancet 2003; 361:13-20.

4. Jackson EA, Moscucci M, Smith DE, et al. The association of sex with outcomes among patients undergoing primary percutaneous coronary intervention for ST elevation myocardial infarction in the contemporary era: Insights from the Blue Cross Blue Shield of Michigan Cardiovascular Consortium (BMC2). Am Heart J 2011; 161(1): 106-12.

5. Prasad A, Stone GW, Aymong E, et al. Impact of STsegment resolution after primary angioplasty on outcomes after myocardial infarction in elderly patients: an analysis from the CADILLAC trial. Am Heart J 2004; 147(4): 669-75. 
6. Gasior M, Pres D, Stasik-Pres G, et al. Does glucose level at hospital discharge predict one-year mortality in patients with diabetes mellitus treated with percutaneous coronary intervention for ST-segment elevation myocardial infarction? Kardiol Pol 2008; 66(1): 1-8.

7. Cho JY, Jeong MH, Ahn Y, et al. High Lipoprotein(a) Levels are Associated With Long-Term Adverse Outcomes in Acute Myocardial Infarction Patients in High Killip Classes. Korean Circ J 2010; 40(10): 4918.

8. Moscucci M, Eagle KA. Door-to-balloon time in primary percutaneous coronary intervention: is the 90-minute gold standard an unreachable chimera? Circulation 2006; 113(8):1048-50.

9. Sadrnia S, Pourmoghaddas M, Hadizadeh M, et al. Factors affecting outcome of primary percutaneous coronary intervention for acute myocardial infarction. ARYAAtheroscler 2013; 9(4): 241-46.

10. Beohar N, Davidson CJ, Weigold G, et al. Predictors of long-term outcomes following direct percutaneous coronary intervention for acute myocardial infarction. Am J Cardiol 2001; 88:1103-7.

11. Geisler T, Muller K, Karathanos A, et al. Impact of antithrombotic treatment on short term outcomes after $\mathrm{PCl}$ of left main disease: a pooled analysis from REPLACE 2, ACUITY, and HORIZONS-AMI trails. Euro intervention 2014; 10(1):97-104

12. Rakowaski T, Suidak Z, Dudek D. Impact of smoking status on outcome of patient with ST segment elevation myocardial infarction treated with primary percutaneous coronary intervention. J Thromb Thrombolysis 2012; 34:397-403.

13. Franklin K, Robert J, Spencer F, et al. Implications of diabetes in patients with coronary syndromes. The global registry of acute coronary events. Arch Intern Med 2004; 164:1457-63.

14. Jensen LO, Maeng M, Thayssen P, et al. Influence of diabetes mellitus on clinical outcomes following primary percutaneous coronary intervention in patients with ST-segment elevation myocardial infarction. Am J Cardiol 2012; 109(5):629-35

15. Willich SN, Muller-Nordhorn J, Kulig M et al. S.N. Willich, J. M "uller-Nordhorn, M. Kulig et al., "Cardiac risk factors, medication, and recurrent clinical events after acute coronary disease: a prospective cohort study," European Heart Journal 2001; 22(4): 307-13.
16. De Luca G, Dirksen MT, Spaulding C, et al. Impact of hypertension on clinical outcome in STEMI patients undergoing primary angioplasty with BMS or DES: insights from the DESERT cooperation. Int J Cardiol; 175:50-4.

17. Yusuf PS, Hawkes S, Ounpuu B et al., "Eûect of potentially modiûable risk factors associated with myocardial infarction in 52 countries (the INTERHEART study): case-control study," Lancet 2004; 364, 9438: 937-952,

18. Sushma P, Suresh P, Purushottam J, et al. A prospective study of Myocardial Infarction patients admitted in a tertiary care hospital of south-eastern Rajasthan. Int J Biol Med Res 2012; 3:1694-96.

19. Weir RA, Mc Murray JJ. Epidemiology of heart failure and LV dysfunction after acute myocardial infarction. Curr Heart failure Rep 2006; 3:175-80.

20. Glenn NL, Eric RB, James $C B$, Steven RB, John AB, Charles EC, Stephen GE. 2015 ACC/AHA/SCAI Focused Update on Primary PCI for Patients with STEMI: An Update of the 2011 ACCF/AHA/SCAI Guideline for Percutaneous Coronary Intervention and the 2013 ACCF/AHA Guideline for the Management of ST-Elevation Myocardial Infarction. Circulation 2016; 133:1135-47.

21. Zhang SY, Hu Dy, Sun YH, et al. Current management of patients with ST elevation myocardial infarction in Metropoliton Beijing. China Clin Invest Ned 2008; 31:189-97.

22. Marieke L, Wounter G, Iwan C. Quantitative analysis of the impact of the total ischemic time on myocardial perfusion and clinical outcome in patient with ST elevated myocardial infarction. Am J Cardiol 2011; 108:1536-41.

23. Fang J, Alderman MH. Dissociation of hospitalization and mortality trends for myocardial infarction in the United States from 1988 to 1997. Am J Med 2002; 113:208.

24. Paul S, Bernard J, David A. et al. Impact of multivessel disease on reperfusion success and clinical outcomes in patients undergoing primary percutaneous coronary intervention for acute myocardial infarction. Eur Heart J 2007; 28:1709-1716

25. Wald DS, Morris JK, Wald NJ, Chase AJ, Edwards RJ, Hughes LO, Berry C, Oldroyd KG, PRAMI Investigators. Randomized trial of preventive angioplasty in myocardial infarction. N Engl J Med. 2013; 369:1115-1123. 
26. Caixeta A, Lansky AJ, Mehran R, et al. Session Title: High- Risk Intervention: STEMI and Left Main Percutaneous Coronary Intervention Abstract 20882: Predictors of Suboptimal TIMI Flow after Primary Angioplasty for Acute Myocardial Infarction: Results from the HORIZONS-AMI Trial. Circulation 2010; 122:208-82.

27. Reddy NR, Aju PR, Kapoor S, et al. Prospective observational study of primary angioplasty of the infarct-related artery for acute myocardial infarction.Indian Heart J 1999; 51:167-72.

28. Hussain A, Siddique MS, Hanif B, et al. Outcomes of primary percutaneous intervention (PCI) in a Tertiary Care Cardiac Centre. JPMA 2009; 59:426-9.
29. Reza AQM, Islam AHMW, Munwar S, Talukder S. Study on primary percutaneous coronary intervention $(\mathrm{PCl})$ in patient with Acute Myocardial Infarction : In hospital; and 30 days survival outcome: Cardiovascular Journal 2010; 2: 212-217

30. Hermanides RS, Ottervanger JP, Dambrink JH, et al. Incidence, predictors and prognostic importance of bleeding after primary $\mathrm{PCl}$ for ST-elevation myocardial infarction. 2010; 6:106-11

31. Grines CL, Browne KF, Marco J, et al. A comparison of immediate angioplasty with thrombolytic therapy for acute myocardial infarction. The primary angioplasty in myocardial infarction study group. N Eng J Med 1993; 328:673-9. 